\title{
Population stratification may bias analysis of PGC-1 $\alpha$ as a modifier of age at Huntington disease motor onset
}

\author{
Eliana Marisa Ramos $\cdot$ Jeanne C. Latourelle $\cdot$ Ji-Hyun Lee $\cdot$ Tammy Gillis $\cdot$ Jayalakshmi S. Mysore $\cdot$ Ferdinando \\ Squitieri • Alba Di Pardo · Stefano Di Donato • Michael R. Hayden · Patrick J. Morrison • Martha Nance • \\ Christopher A. Ross · Russell L. Margolis · Estrella Gomez-Tortosa • Carmen Ayuso • Oksana Suchowersky • \\ Ronald J. Trent $\cdot$ Elizabeth McCusker $\cdot$ Andrea Novelletto $\cdot$ Marina Frontali $\cdot$ Randi Jones $\cdot$ Tetsuo Ashizawa $\cdot$ \\ Samuel Frank • Marie-Helene Saint-Hilaire · Steven M. Hersch · Herminia D. Rosas • Diane Lucente • \\ Madaline B. Harrison · Andrea Zanko · Karen Marder · James F. Gusella · Jong-Min Lee · Isabel Alonso • \\ Jorge Sequeiros $\cdot$ Richard H. Myers $\cdot$ Marcy E. MacDonald
}

Received: 23 March 2012 / Accepted: 11 July 2012 / Published online: 25 July 2012

(C) The Author(s) 2012. This article is published with open access at Springerlink.com

\begin{abstract}
Huntington's disease (HD) is an inherited neurodegenerative disorder characterized by motor, cognitive and behavioral disturbances, caused by the expansion of a CAG trinucleotide repeat in the HD gene. The CAG allele size is the major determinant of age at onset (AO) of motor symptoms, although the remaining variance in $\mathrm{AO}$ is highly
\end{abstract}

E. M. Ramos · J.-H. Lee · T. Gillis · J. S. Mysore · D. Lucente · J. F. Gusella $\cdot$ J.-M. Lee $\cdot$ M. E. MacDonald $(\bowtie)$

Center for Human Genetic Research, Massachusetts General

Hospital, Simches Research Building, Room 5414,

185 Cambridge Street, Boston, MA 02114, USA

e-mail: macdonam@helix.mgh.harvard.edu

E. M. Ramos - I. Alonso · J. Sequeiros

UnIGENe, IBMC, Institute for Molecular and Cell Biology,

University of Porto, Porto, Portugal

J. C. Latourelle $\cdot$ S. Frank · M.-H. Saint-Hilaire $\cdot$ R. H. Myers Department of Neurology, Boston University School of Medicine, Boston, MA 02118, USA

F. Squitieri · A. Di Pardo

Centre for Neurogenetics and Rare Diseases, IRCCS Neuromed, 86077 Pozzilli (IS), Italy

\section{S. Di Donato}

Fondazione IRCCS Istituto Neurologico Carlo Besta, via Celoria 11 20133, Milan, Italy

M. R. Hayden

Center for Molecular Medicine and Therapeutics, University

of British Columbia, Vancouver, BC V5Z 4H4, Canada

P. J. Morrison

Regional Medical Genetics Centre, Belfast HSC Trust, Belfast BT9 7AB, UK

P. J. Morrison

University of Ulster, Cromore Road, Coleraine BT52 15A, UK heritable. The rs7665116 SNP in PPARGC1A, encoding the mitochondrial regulator PGC- $1 \alpha$, has been reported to be a significant modifier of AO in three European HD cohorts, perhaps due to affected cases from Italy. We attempted to replicate these findings in a large collection of $(1,727) \mathrm{HD}$ patient DNA samples of European origin. In the entire

M. Nance

Hennepin County Medical Center, 701 Park Avenue, Minneapolis, MN 55415, USA

C. A. Ross - R. L. Margolis

Department of Psychiatry and Behavioral Sciences,

Johns Hopkins University, Baltimore, MD 21287, USA

E. Gomez-Tortosa

Department of Neurology, Fundación Jiménez Diaz,

28040 Madrid, Spain

C. Ayuso

Department of Genetics, IIS, Fundación Jiménez Diaz, CIBERER, 28040 Madrid, Spain

O. Suchowersky

Departments of Medicine and Medical Genetics,

University of Alberta, Edmonton, AB T6G 2B7, Canada

R. J. Trent

Sydney Medical School, University of Sydney, Sydney,

NSW 2006, Australia

E. McCusker

Department of Neurology, Westmead Hospital,

Westmead Sydney, NSW 2145, Australia

A. Novelletto

Department of Biology, University Tor Vergata,

00133 Rome, Italy 
cohort, rs7665116 showed a significant effect in the dominant model $(p$ value $=0.008)$ and the additive model ( $p$ value $=0.009)$. However, when examined by origin, cases of Southern European origin had an increased rs7665116 minor allele frequency (MAF), consistent with this being an ancestry-tagging SNP. The Southern European cases, despite similar mean CAG allele size, had a significantly older mean AO $(p<0.001)$, suggesting population-dependent phenotype stratification. When the generalized estimating equations models were adjusted for ancestry, the effect of the rs7665116 genotype on AO decreased dramatically. Our results do not support rs7665116 as a modifier of $\mathrm{AO}$ of motor symptoms, as we found evidence for a dramatic effect of phenotypic (AO) and genotypic (MAF) stratification among European cohorts that was not considered in previously reported association studies. A significantly older AO in Southern Europe may reflect population differences in genetic or environmental factors that warrant further investigation.

\section{Introduction}

Huntington's disease (HD) is a neurodegenerative disorder with classic symptoms that include progressive chorea, motor deficits, cognitive changes and dementia. Age at onset (AO) of the overt symptoms is highly variable: while some individuals show signs in the first decade, others remain asymptomatic even after 60 years of age, though in most cases death follows on average about 17 years after the first symptoms. HD is inherited as an autosomal domi- nant trait and is caused by the expansion of an unstable CAG repeat, in the first exon of the HD gene (now called HTT), on chromosome 4p16.3 (The Huntington's Disease Collaborative Research Group 1993), resulting in an expanded polyglutamine tract in the huntingtin protein.

The major determinant of $\mathrm{AO}$ in $\mathrm{HD}$ is the size of the expanded CAG repeat allele (Lee et al. 2012), such that the longer the repeat the earlier the onset of clinical symptoms, though most HD cases occur in adulthood with about 40-45 CAG repeats. Repeat length alone explains about $70 \%$ of the variability in onset age (Duyao et al. 1993). The remaining variance in $\mathrm{AO}$ (residual $\mathrm{AO}$ ) is highly heritable but remains unexplained. Nonetheless, recent genetic studies have nominated about 20 loci that may modify AO or progression of HD. However, many of the specific polymorphisms assessed in multiple studies have failed to be replicated, including attractive biological candidate genes such as glutamate receptor, ionotropic kainate 2 (GRIK2), apolipoprotein E (APOE) and brain-derived neurotrophic factor (BDNF) (Rubinsztein et al. 1997; Metzger et al. 2006; Panas et al. 1999; Alberch et al. 2005; Di Maria et al. 2006).

One biologically compelling candidate thought to be involved in HD pathogenesis is PPARGCIA, localized at 4p15.1-2, which encodes peroxisome proliferator-activated receptor $\gamma$ coactivator $1 \alpha$ (PGC- $1 \alpha)$, a transcriptional regulator of adaptive thermogenesis (Puigserver et al. 1998) and mitochondrial respiration and oxidative stress (Puigserver and Spiegelman 2003; St-Pierre et al. 2006). The lack of PGC- $1 \alpha$ expression produces an HD-like phenotype in mice (Lin et al. 2004; Leone et al. 2005) and mutant, but
M. Frontali

Institute of Translational Pharmacology,

CNR 00133 Rome, Italy

R. Jones

Department of Neurology, Emory University,

Atlanta, GA 30329, USA

T. Ashizawa

Department of Neurology, University of Florida,

Gainesville, FL 32610, USA

S. M. Hersch · H. D. Rosas

MIND, Massachusetts General Hospital,

114 16th Street, Charlestown, MA 02129, USA

M. B. Harrison

Department of Neurology, University of Virginia,

Charlottesville, VA 22908, USA

A. Zanko

Department of Pediatrics, University of California,

San Francisco, CA 94143, USA

\section{K. Marder}

College of Physicians and Surgeons, Columbia University, New York, NY 10032, USA

J. F. Gusella · J.-M. Lee · M. E. MacDonald

Harvard Medical School and Program in Medical and Population Genetics, Broad Institute of Harvard and Massachusetts Institute of Technology, Cambridge, MA 02142, USA

I. Alonso $\cdot$ J. Sequeiros

CGPP, IBMC, Institute for Molecular and Cell Biology,

University of Porto, Porto, Portugal

I. Alonso $\cdot$ J. Sequeiros

ICBAS, Instituto de Ciências Biomédicas Abel Salazar,

University of Porto, Porto, Portugal 
not wild type, huntingtin down-regulates the expression of PGC- $1 \alpha$ and its target genes (Cui et al. 2006; Lin et al. 2004; Weydt et al. 2006). Moreover, three recent studies, with DNA samples from European HD patients, mainly from Italy and Germany, have reported an association of PGC-1 $\alpha$ with AO of HD symptoms (Che et al. 2011; Weydt et al. 2009; Taherzadeh-Fard et al. 2009). Although different sets of PPARGC1A SNPs were included in these studies, one polymorphism (rs7665116), located at the $3^{\prime}$-end region of intron 2, was associated with a later $\mathrm{AO}$ in all three studies, displaying a significant effect both in an additive and dominant model. Following these results, it was reported that polymorphisms in PGC- $1 \alpha$ downstream target genes, namely nuclear respiratory factor $1(N R F 1)$ and mitochondrial transcription factor A (TFAM), may influence the AO in HD (Taherzadeh-Fard et al. 2011). Given that results based on analyses of the PPARGC1A rs7665116 SNP are motivating a broader range of research into the functional basis of the effect, the aim of the present study was to attempt to replicate the association of this SNP with $\mathrm{AO}$, in a much larger cohort of 1,727 HD patients of different European populations.

\section{Methods}

\section{Subjects}

We analyzed 1,929 HD patients with known $\mathrm{AO}$ of overt motor symptoms. The DNA samples were from subjects involved in long-term genetic studies from collaborating investigators (HD-MAPS), the HD observational study COHORT and from the Harvard Tissue Resource Center Bank (McLean's Hospital, Belmont MA) and the National Neurological Research Bank (VAMC Wadsworth Division, Los Angeles CA). These studies included related individuals [from 1,676 different families defined either based on the likelihood of genetic similarity from genome-wide genotyping information (Western European samples) or membership in nuclear (parents and children) families (Southern European samples)]. Of these, 934 were selfreported as originally from Southern European countries (263 from Portugal, 664 from Italy, 5 from Spain and 2 from Greece), the rest of the cases had unconfirmed or no geographical origin data. 1,020 of these were genotyped using the GeneChip Human Mapping 500K Array Set (Affymetrix) at the Broad Institute of Harvard and MIT as part of a genome-wide scan for HD genetic modifiers.

\section{Genotyping}

The HD CAG repeat length was determined by a polymerase chain reaction (PCR) amplification assay, using fluores- cently labeled primers, as previously described (Warner et al. 1993). The size of the fragments was determined using the ABI PRISM 3730xl automated DNA Sequencer (Applied Biosystems, Foster City, CA, USA) and GeneMapper version 3.7 software. A set of HD CAG alleles, determined by DNA sequencing, were used as standards. Genotyping of the PGC- $1 \alpha$ polymorphism (rs7665116) was performed by real-time PCR using the commercially available Taqman Genotyping probe (Applied Biosystems, Foster City, CA, USA) carried out on the LightCycler ${ }^{\circledR} 480$ (Roche Diagnostics, Mannheim), following manufacturer's instructions.

\section{Statistics}

For the 1,020 samples with whole-genome genotyping, PCA was carried out using PLINK v1.05 (http:// pngu.mgh.harvard.edu/Purcell/plink/) (Purcell et al. 2007) in order to determine the genetic ancestry of these individuals. Briefly, genotypes of HD samples were combined with HapMap Phase 2 data (CEPH, Yoruba, Han-Chinese and Japanese populations) for pairwise IBD estimation and subsequent IBS clustering.

To assess differences in the mean motor AO among Western and Southern European samples, we used the general estimating equation (GEE), thereby adjusting for related samples. Multivariate analyses were generated using GEE to assess the effect of the rs7655116 SNP at the PGC- $1 \alpha$ gene with HD residual motor onset, adjusting for familial correlation. Residual motor onsets were computed as the difference between the observed and expected age of onset and were standardized to a mean of zero and standard deviation of one. The weighted GEE was computed assuming an independent correlation structure and using the robust estimator of the variance to account for familial relationships. All statistical analyses were performed using PASW Statistics (version 18).

\section{Results}

We genotyped a collection of 1,929 HD DNA samples, with known HD CAG allele sizes and known age at onset of motor symptoms, for the PPARGC1A rs7665116 polymorphism. The observed genotype frequency of this SNP was in Hardy-Weinberg equilibrium. Since, in two of the previous reports, the association with $\mathrm{AO}$ was primarily observed in HD patients of Italian ancestry (Che et al. 2011; Weydt et al. 2009); we split our large cohort by ancestry into either Southern European or Western European HD cases. The Southern European HD cases $(n=934)$ consisted of self-reported Portuguese $(n=263)$, Italian $(n=664)$, Spanish $(n=5)$ and Greek $(n=2)$ HD cases. The 
Table 1 Genetic and clinical data among European cases of Western and Southern origin

\begin{tabular}{|c|c|c|c|c|c|c|c|c|}
\hline \multirow[t]{2}{*}{ Origin of samples } & \multicolumn{4}{|c|}{ 36-87 HD CAG range } & \multicolumn{4}{|c|}{ 40-53 HD CAG range } \\
\hline & $\begin{array}{l}\text { Number } \\
\text { of samples }\end{array}$ & $\begin{array}{l}\text { Mean HD } \\
\text { CAG (median) }\end{array}$ & $\begin{array}{l}\text { Mean Motor } \\
\text { Onset (median) }\end{array}$ & $\begin{array}{l}\text { rs7665116 } \\
\text { MAF }\end{array}$ & $\begin{array}{l}\text { Number } \\
\text { of samples }\end{array}$ & $\begin{array}{l}\text { Mean HD } \\
\text { CAG (median) }\end{array}$ & $\begin{array}{l}\text { Mean Motor } \\
\text { Onset (median) }\end{array}$ & $\begin{array}{l}\text { rs } 7665116 \\
\text { MAF }\end{array}$ \\
\hline Southern European ${ }^{\mathrm{a}}$ & 934 & $44.29(43)$ & $47.34(48)$ & 0.169 & 879 & $43.73(43)$ & $48.04(48)$ & 0.173 \\
\hline Western European ${ }^{\mathrm{b}}$ & 793 & $44.78(44)$ & $43.20(43)$ & 0.119 & 749 & $44.32(44)$ & $43.83(43)$ & 0.118 \\
\hline Total European & 1,727 & $44.52(43)$ & $45.44(45)$ & 0.146 & 1,628 & $44.00(43)$ & $46.10(46)$ & 0.148 \\
\hline
\end{tabular}

a Self-reported

b Genetic background confirmed

Western European HD cases were chosen from amongst another 1,020 HD patients by use of principal component analysis (PCA) on available whole-genome genotyping data, to infer their genetic background. The first principal component $(\mathrm{PC} 1)$ distinguished Africans from non-Africans and the second principal component (PC2) distinguished Africans and Europeans from Asians (data not shown), and allowed us to exclude from our analysis the few samples who had significant contribution of either Asian or African ancestry. Among the remaining $(n=952)$ European cases, the Western European cluster $(n=793)$ was defined by overlap with the US Northern-Western European origin CEPH (HapMap) cluster, and consisted mainly of persons with self-reported North-American origin (Canada and US) as well as French and Irish. Thus, we had a total of 1,727 HD patients with assigned ancestry; 934 Southern European and 793 Western European (Table 1).

Remarkably, analysis of the clinical data for these 1,727 HD cases, which had CAG alleles ranging from 36 to 87 repeats, revealed that the self-reported Southern Europeans $(n=934)$ had significantly later onset of motor HD symptoms $(\mathrm{p}<0.001)$, by $4-5$ years, compared to the Western European $(n=793)$, though the means/medians for HD CAG repeat length were similar in both groups (Table 1). Furthermore, the observed rs7665116 genotypes for samples from the Southern European countries revealed higher minor allele frequency (MAF) $(\sim 17 \%)$ when compared to the Western European set $(\sim 12 \%)$ (Table 1$)$. These findings, together with the striking differences in the MAF of this polymorphism among the different HapMap populations, strongly suggested that population stratification might increase type I errors in the AO association analysis.

Finally, we have recently shown that the non-normal distribution of CAG allele size (and AO) also introduces error in conventional statistical analysis (Lee et al. 2012). Even a single CAG outlier sample, with a very long CAG repeat and extremely young age at onset relative to all others, can have a profound effect on the final result when testing for the effects of potential genetic modifiers (Lee et al. 2012). Therefore, as a final filter, we chose only the Southern and Western European HD cases with CAG alleles in the 40- to

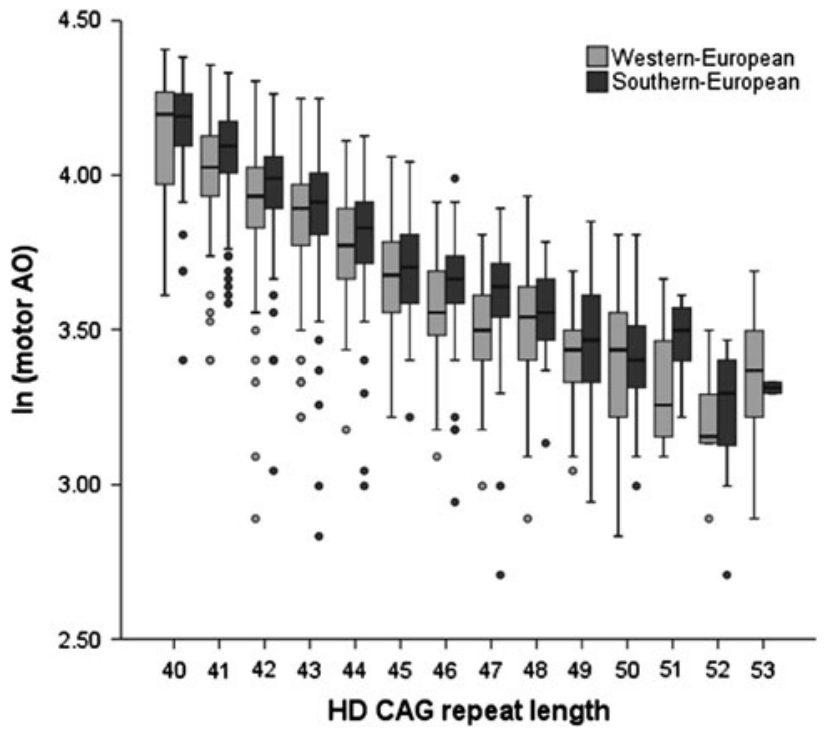

Fig. 1 Variance of age at motor onset for HD cases of Western and Southern European origin. A box plot depicting the relationship of the natural log-transformed age at onset of motor symptoms to the expanded CAG allele size, for patients in the 40-53 CAG range, illustrating that self-reported Southern Europeans had an older age at onset across the spectrum of allele sizes. Circles are outliers defined by a standard quartile method (outside of 1.5 times interquartile range), some of which could reflect errors in the motor AO data while others may represent true biological outliers

53-repeat range, shown previously to yield a statistically well-behaved data set that conforms to the fundamental assumptions of linear regression analysis (constant variance and normally distributed error) (Lee et al. 2012).

As summarized in Table 1, these filtering steps yielded a total of 879 self-reported Southern European cases from 823 families and 749 Western European cases (matched by use of PCA) from 620 different families, with CAG repeats ranging from 40 to 53 repeats. Notably, as observed for the larger set of HD patients with a broader CAG repeat range, in this final set of 1,628 patients the self-reported Southern Europeans had a significantly older mean age at onset of motor symptoms than Western Europeans (Table 1), which was observed across the spectrum of CAG allele sizes (Fig. 1), despite a similar mean/median HD CAG repeat 
size (Table 1). Furthermore, the rs7665116 MAF was higher in the former relative to the latter Western European patients (Table 1).

Using this final set of 1,628 HD patients, we then performed analysis to determine whether rs7665116 may contribute to variance in HD motor onset not explained by the length of the expanded CAG repeat. In order to adjust for familial relationships, the effect of the rs7665116 on residual motor onset was calculated using generalized estimating equations (GEE). In the unadjusted analysis, a significant association with later residual $\mathrm{AO}$ was observed for both the additive genetic model $(\beta=0.090, p$ value $=$ $0.009)$ and the dominant model $(\beta=0.113, p$ value $=$ 0.008) (Table 2). However, adjusting the analysis for ancestry (Southern vs. Western European), in both the additive and the dominant models, produced a striking impact on the effect sizes ( $\beta$ decreased by $\sim 25 \%$ ) and the $p$ values ( $p$ increased $\sim 4 \times$ ) (Table 2 ), thereby revealing that population stratification is a large contributor to an apparent rs7665116 association.

\section{Discussion}

Previous studies have reported the presence of a common polymorphism in PPARGC1A (rs7665116) that is associated with a delay in AO of HD motor symptoms in three European HD cohorts (Che et al. 2011; Taherzadeh-Fard et al. 2009; Weydt et al. 2009), primarily contributed by patients from Italy. Our study, which involved a larger collection of HD cases, did not provide strong evidence for this SNP, and therefore, for PGC- $1 \alpha$ as a modifier of HD motor onset, but did strongly support further investigation of the factors that contribute to the striking differences in AO of motor symptoms in 'Southern Europeans'.
The results of our study expose genetic ancestry as a critical factor in HD association studies. It is expected that a disease-associated polymorphism may have varying effects in different populations, but the variation in minor allele frequency, across different genetic backgrounds related to ancestry may also be critical and should be taken into account in genetic association analysis. Cases that are poorly matched for genetic background may lead to false positives in association studies. It is important to control for ancestry by use of PCA or related methods, even in apparently close related populations such as Europeans (Novembre et al. 2008) where there is strong evidence of recent population selection that has led to intra-European variation in allele frequency (Price et al. 2008). This is particularly important in studies using the CEPH-CEU panel as controls since the genetic matching to different populations may differ considerably in different countries (Lao et al. 2008). It is difficult to accurately infer ancestry in candidate gene association studies, leading to imperfect correction for stratification. However, with increasing availability of genome-wide datasets, the assessment of population structure should become a common procedure for candidate association studies.

Our study points out the dramatic effect that population stratification can have in testing a candidate gene for an association with disease phenotype. We found that the variation in rs7665116 minor allele frequency could lead to a false positive, if genetic ancestry is not corrected for in the analysis. The Southern European cases seem to be different genetically and clinically, in terms of age at diagnosis of motor symptoms, from other European samples. By adjusting for ancestry, we observed striking effects on both the $\mathrm{P}$ values (increased $\sim 4 \times$ ) and effect sizes (decreased by $\sim 25 \%$ ). Even though the post-adjustment $p$ values remained nominally significant, the dramatic reduction in significance occasioned by considering ancestry does not
Table 2 Multivariate correlation of rs7665116 with residual age at motor onset

* $p$ values were derived using GEE to account for familial relationships

\begin{tabular}{|c|c|c|c|c|c|}
\hline Model & $\begin{array}{l}\text { Standardized } \\
\text { coefficient }\end{array}$ & $\begin{array}{l}\text { Standard } \\
\text { error }\end{array}$ & \multicolumn{2}{|c|}{$\begin{array}{l}95 \% \text { confidence } \\
\text { limits }\end{array}$} & $p$ value* \\
\hline \multicolumn{6}{|l|}{ Additive } \\
\hline \multicolumn{6}{|l|}{ PGC $1 \alpha$ rs 7665116} \\
\hline $\mathrm{T}-\mathrm{T}$ vs. $\mathrm{T}-\mathrm{C}$ vs. $\mathrm{C}-\mathrm{C}$ & 0.090 & 0.0348 & 0.022 & 0.158 & 0.009 \\
\hline \multicolumn{6}{|c|}{ PGC $1 \propto$ rs $7665116+$ ancestry } \\
\hline $\mathrm{T}-\mathrm{T}$ vs. $\mathrm{T}-\mathrm{C}$ vs. $\mathrm{C}-\mathrm{C}$ & 0.069 & 0.0345 & 0.001 & 0.136 & 0.047 \\
\hline WE vs. SE & 0.208 & 0.0416 & 0.127 & 0.290 & $<0.001$ \\
\hline \multicolumn{6}{|l|}{ Dominant } \\
\hline \multicolumn{6}{|l|}{ PGC1 $\alpha$ rs7665116 } \\
\hline $\mathrm{T}-\mathrm{T}$ vs. $\mathrm{T}-\mathrm{C}+\mathrm{C}-\mathrm{C}$ & 0.113 & 0.0424 & 0.029 & 0.196 & 0.008 \\
\hline \multicolumn{6}{|c|}{ PGC $1 \alpha$ rs7665116 + ancestry } \\
\hline $\mathrm{T}-\mathrm{T}$ vs. $\mathrm{T}-\mathrm{C}+\mathrm{C}-\mathrm{C}$ & 0.089 & 0.0418 & 0.007 & 0.171 & $\mathbf{0 . 0 3 3}$ \\
\hline WE vs. SE & 0.208 & 0.0415 & 0.127 & 0.289 & $<0.001$ \\
\hline
\end{tabular}


lend confidence to its being a true effect and rather suggests that it is due to insufficiently rigorous ancestry categorization of the 'Southern European' set, which was based solely on self-reporting rather than unbiased genome-wide genotyping data. Consistent with this interpretation, while this manuscript was under review, an article by Soyal et al. (2012) reported that no association of rs7651166 with AO to first symptom (not necessarily motor) was found in an European cohort of 1,706 HD patients whose MAF for this SNP closely resembled the MAF that we report for the Western European samples in our study.

A remarkable finding from our analysis is the strong evidence of later motor onset for HD patients originally from Southern European countries (Portugal and Italy), which have a reported onset of motor symptoms that is $4-5$ years later than that of HD patients from other European regions, despite similar mean/median CAG allele size. This striking difference may reflect population differences elsewhere in the genome, since extensive genome-wide SNP analyses have shown that even though European populations share much of their genetic background, they also exhibit a notable degree of non-sharing (ancestry) (Lao et al. 2008; Novembre et al. 2008). It's important to note that in addition to genetic background differences, a number of other factors may contribute to the difference in age at onset. One possibility is environmental influences, for example, differences related to lifestyle, or perhaps types of medication. A meta-analysis study has found evidence that people who adhere to a Mediterranean Diet appear to have a reduced risk of developing Parkinson's and Alzheimer's disease (Sofi et al. 2008), and altered Alzheimer's disease course (Scarmeas et al. 2007). A recent observational study of HD in Europe has shown that Southern European (and Polish) clinicians prescribed anti-dyskinetic medication more frequently than clinicians in other European regions (Orth et al. 2010). Another environment related factor that is likely to contribute are the criteria and procedures for diagnosing HD, which may differ in different cultures. It is now important to understand which of many potential population-specific genetic and/or environmental factors are associated with later reported $\mathrm{AO}$ of motor symptoms in Southern Europeans.

\section{Conclusion}

The results of our study do not provide strong evidence for PPARGC1A SNP rs7665116, and therefore, for PGC- $1 \alpha$, as a modifier of age at onset of HD motor symptoms. However, we have found evidence of a significantly later age at onset of motor symptoms in Southern European countries, which may reflect genetic effects and/or environmental (lifestyle, diagnosis) factors that should be further explored.
Our data strongly illustrate the false contribution that population stratification may make in a candidate gene association study, while providing genetic evidence that the contribution of PGC- $1 \alpha$ as a modifier of the disease process that leads to onset of HD motor symptoms may not be significant.

Acknowledgments We thank the HD families, whose participation in genetic studies made this work possible, the COHORT co-investigators and contributors (see "Appendix"), contributors to the HD-MAPS study, Ruth Abramson, Alexandra Durr, Adam Rosenblatt, Luigi Frati, Susan Perlman, P. Michael Conneally, Mary Lou Klimek, Melissa Diggin, Tiffany Hadzi and Ayana Duckett, as well as the Harvard Brain Tissue Resource Center at McLean Hospital and the National Neurological Research Specimen Bank at the VA West Los Angeles Healthcare Center. EMR is the recipient of a scholarship from the Fundação para a Ciência e a Tecnologia of Portugal (SFRH/BD/44335/2008). Study funding supported by NIH grants from the NINDS NS16367 (The Massachusetts HD Center Without Walls) and NS32765, and the CHDI Foundation, Inc.

Conflict of interest The authors declare that they have no conflict of interest.

Ethical Standards This study used only deidentified, previously collected DNA samples and phenotypic data in a manner approved by the Institutional Review Board of Partners HealthCare, Inc.

Open Access This article is distributed under the terms of the Creative Commons Attribution License which permits any use, distribution, and reproduction in any medium, provided the original author(s) and the source are credited.

\section{Appendix: Huntington Study Group COHORT Investigators}

Steering Committee

University of Rochester, Rochester, NY: Ira Shoulson, MD (principal investigator), James Gusella, $\mathrm{PhD}$ (co-principal investigator), Tatiana Foroud (co-principal investigator), Irina Antonijevic, Dan van Kammen (CHDI Foundation Inc.).

Publications and Data Use Committee

Tatiana Foroud (Chair), Ray Dorsey (Co-Chair), John Warner (CHDI), Joe Giuliano, Louise Vetter, Oksana Suchowersky, Christopher Beck, David Oakes.

Participating Investigators and Coordinators

F. Marshall, University of Rochester; K. Marder, S. Frucht, C. Moskowitz, R. Clouse, P. Wasserman, Columbia University Medical Center; K. Shannon, J. Jaglin, Rush University Medical Center; 
J. Jankovic, A. Palao, Baylor College of Medicine;

M. Harrison, University of Virginia;

C. Singer, M. Quesada, University of Miami;

S. Hersch, D. Rosas, K. Tanev, K. Malarick, Massachusetts

General Hospital;

A. Colcher, University of Pennsylvania;

J. Sanchez-Ramos, University of South Florida;

S. Kostyk, Ohio State University;

J. Paulsen, University of Iowa;

J. Perlmutter, S. Tabbal, Washington University;

C. Ross, F. Nucifora, Johns Hopkins University;

R. Dubinsky, H. Dubinsky, University of Kansas Medical

Center;

O. Suchowersky, M.L. Klimek, University of Calgary

R. Jones, C. Testa, S. Factor, Emory University School of

Medicine;

D. Jennings, Institute for Neurological Disorders

J. Morgan, Medical College of Georgia;

D. Higgins, E. Mohlo, Albany Medical College;

J. Adams, The Centre for Addiction and Mental Health,

Toronto, Canada;

S. Frank, M. Saint-Hilaire, M. Diggin, Boston University;

S. Furtado, University of Alberta

F. Walker, C. O'Neill, V. Hunt, Wake Forest University School of Medicine;

K. Quaid, Indiana University School of Medicine;

M. LeDoux, University of Tennessee Health Science Center;

L. Raymond, B. Leavitt, J. Decolongon, University of British Columbia, Canada;

S. Perlman, University of California, Los Angeles

J. Corey-Bloom, G. Peavy, J. Goldstein, University of California San Diego;

R. Kumar, Colorado Neurological Institute;

E. McCusker, J. Griffith, C. Loy, Westmead Hospital, NSW, Australia;

V. Wheelock, T. Tempkin, A. Martin, University of California Davis;

M. Nance, Hennepin County Medical Center;

U. Kang, University of Chicago;

W. Mallonee, G. Suter, Hereditary Neurological Disease Center, Kansas;

F. Revilla, M. Gartner University of Cincinnati/Cincinnati Children's Hospital;

C. Drazinic, M.J. Fitzpatrick, University of Connecticut;

M. Panisset, Hôtel-Dieu Hôpital-CHUM, Canada;

K. Duff, University of Utah

B. Scott, Duke University Medical Center;

W. Weiner, B. Robottom, University of Maryland School of Medicine;

E. Chiu, O. Yastrubetskaya, A. Churchyard, St Vincent's Aged Mental Health Service (SVAMHS) Melbourne, Australia;

T. J. Greenamyre, University of Pittsburgh;
P. Agarwal, Booth Gardner Parkinson's Care Center, WA. Biostatistics/Coordination Center: University of Rochester-D. Oakes, C. Beck, S. Robertson, K. Eaton, P. Lindsay, L. Deuel.

DNA Genotyping Center: M. MacDonald, Center for Human Genetic Research, Massachusetts General Hospital.

Contributors

C. Hickey, University of Rochester; L. Muratori, E. Louis, Columbia University Medical Center; A. Leserman, N. Doucette, Ohio State University; E. Uc, R. Rodnitzky, S. Vik, University of Iowa, R. Davis, S. Dietrich, University of Virginia; V. Segro, D. Erickson, Colorado Neurological Institute; V. Hunt, Wake Forest University School of Medicine; N. Lucarelli, University of Pittsburgh; J. Broyles, University of Kansas Medical Center; J. DeLaRosa, University of Texas (Galveston); E. Louis, Columbia University Medical Center; P. Panegyres, Neurodegenerative Disorders Research, WA, AUS; A. Schmidt, S. Barton, Washington University; E. Sperin, C. Testa, Emory University; F. Thiede, University of California, Los Angeles; S. E. Zauber, M. Wesson, Indiana University; R. McInnis, Massachusetts General Hospital; C. Welsh, Johns Hopkins University; M. Wesson, Indiana University School of Medicine; A. Coleman, University of British Columbia, Canada.

\section{References}

Alberch J, Lopez M, Badenas C, Carrasco JL, Mila M, Munoz E, Canals JM (2005) Association between BDNF Val66Met polymorphism and age at onset in Huntington disease. Neurology 65(6):964-965. doi:10.1212/01.wnl.0000175977.57661.b1

Che HV, Metzger S, Portal E, Deyle C, Riess O, Nguyen HP (2011) Localization of sequence variations in PGC-1alpha influence their modifying effect in Huntington disease. Mol Neurodegener 6(1):1. doi:10.1186/1750-1326-6-1

Cui L, Jeong H, Borovecki F, Parkhurst CN, Tanese N, Krainc D (2006) Transcriptional repression of PGC-1alpha by mutant huntingtin leads to mitochondrial dysfunction and neurodegeneration. Cell 127(1):59-69. doi:10.1016/j.cell.2006.09.015

Di Maria E, Marasco A, Tartari M, Ciotti P, Abbruzzese G, Novelli G, Bellone E, Cattaneo E, Mandich P (2006) No evidence of association between BDNF gene variants and age-at-onset of Huntington's disease. Neurobio Dis 24(2):274-279. doi:10.1016/ j.nbd.2006.07.002

Duyao M, Ambrose C, Myers R, Novelletto A, Persichetti F, Frontali M, Folstein S, Ross C, Franz M, Abbott M, Gray J, Conneally P, Young A, Penney J, Hollingsworth Z, Shoulson I, Lazzarini A, Falek A, Koroshetz W, Sax D, Bird E, Vonsattel J, Bonilla E, Alvir J, Bickham Conde J, Cha J-H, Dure L, Gomez F, Ramos M, Sanchez-Ramos J, Snodgrass S, de Young M, Wexler N, Moscowitz C, Penchaszadeh G, MacFarlane H, Anderson M, Jenkins B, Srinidhi J, Barnes G, Gusella JF, MacDonald M (1993) Trinucleotide repeat length instability and age of onset in Huntington's disease. Nat Genet 4(4):387-392. doi:10.1038/ng0893-387 
Lao O, Lu TT, Nothnagel M, Junge O, Freitag-Wolf S, Caliebe A, Balascakova M, Bertranpetit J, Bindoff LA, Comas D, Holmlund G, Kouvatsi A, Macek M, Mollet I, Parson W, Palo J, Ploski R, Sajantila A, Tagliabracci A, Gether U, Werge T, Rivadeneira F, Hofman A, Uitterlinden AG, Gieger C, Wichmann HE, Ruther A, Schreiber S, Becker C, Nurnberg P, Nelson MR, Krawczak M, Kayser M (2008) Correlation between genetic and geographic structure in Europe. Curr Biol 18(16):1241-1248. doi:10.1016/ j.cub.2008.07.049

Lee JM, Ramos EM, Lee JH, Gillis T, Mysore JS, Hayden MR, Warby SC, Morrison P, Nance M, Ross CA, Margolis RL, Squitieri F, Orobello S, Di Donato S, Gomez-Tortosa E, Ayuso C, Suchowersky O, Trent RJ, McCusker E, Novelletto A, Frontali M, Jones R, Ashizawa T, Frank S, Saint-Hilaire MH, Hersch SM, Rosas HD, Lucente D, Harrison MB, Zanko A, Abramson RK, Marder K, Sequeiros J, Paulsen JS, Landwehrmeyer GB, Myers RH, Macdonald ME, Gusella JF (2012) CAG repeat expansion in Huntington disease determines age at onset in a fully dominant fashion. Neurology 78(10):690-695. doi:10.1212/WNL.0b013e318249f683

Leone TC, Lehman JJ, Finck BN, Schaeffer PJ, Wende AR, Boudina S, Courtois M, Wozniak DF, Sambandam N, Bernal-Mizrachi C, Chen Z, Holloszy JO, Medeiros DM, Schmidt RE, Saffitz JE, Abel ED, Semenkovich CF, Kelly DP (2005) PGC-1alpha deficiency causes multi-system energy metabolic derangements: muscle dysfunction, abnormal weight control and hepatic steatosis. PLoS Biol 3(4):e101. doi:10.1371/journal.pbio.0030101

Lin J, Wu PH, Tarr PT, Lindenberg KS, St-Pierre J, Zhang CY, Mootha VK, Jager S, Vianna CR, Reznick RM, Cui L, Manieri M, Donovan MX, Wu Z, Cooper MP, Fan MC, Rohas LM, Zavacki AM, Cinti S, Shulman GI, Lowell BB, Krainc D, Spiegelman BM (2004) Defects in adaptive energy metabolism with CNS-linked hyperactivity in PGC-1alpha null mice. Cell 119(1):121-135. doi:10.1016/j.cell.2004.09.013

Metzger S, Bauer P, Tomiuk J, Laccone F, Didonato S, Gellera C, Mariotti C, Lange HW, Weirich-Schwaiger H, Wenning GK, Seppi K, Melegh B, Havasi V, Baliko L, Wieczorek S, Zaremba J, Hoffman-Zacharska D, Sulek A, Basak AN, Soydan E, Zidovska J, Kebrdlova V, Pandolfo M, Ribai P, Kadasi L, Kvasnicova M, Weber BH, Kreuz F, Dose M, Stuhrmann M, Riess O (2006) Genetic analysis of candidate genes modifying the age-at-onset in Huntington's disease. Hum Genet 120(2):285-292. doi:10.1007/ s00439-006-0221-2

Novembre J, Johnson T, Bryc K, Kutalik Z, Boyko AR, Auton A, Indap A, King KS, Bergmann S, Nelson MR, Stephens M, Bustamante CD (2008) Genes mirror geography within Europe. Nature 456(7218):98-101. doi:10.1038/nature07331

Orth M, Handley OJ, Schwenke C, Dunnett SB, Craufurd D, Ho AK, Wild E, Tabrizi SJ, Landwehrmeyer GB (2010) Observing Huntington's disease: the European Huntington's Disease Network's REGISTRY. PLoS Curr 2. doi:10.1371/currents.RRN1184

Panas M, Avramopoulos D, Karadima G, Petersen MB, Vassilopoulos D (1999) Apolipoprotein E and presenilin-1 genotypes in Huntington's disease. J Neurol 246(7):574-577. doi:10.1007/ s004150050406

Price AL, Butler J, Patterson N, Capelli C, Pascali VL, Scarnicci F, Ruiz-Linares A, Groop L, Saetta AA, Korkolopoulou P, Seligsohn U, Waliszewska A, Schirmer C, Ardlie K, Ramos A, Nemesh J, Arbeitman L, Goldstein DB, Reich D, Hirschhorn JN (2008) Discerning the ancestry of European Americans in genetic association studies. PLoS Genet 4(1):e236. doi:10.1371/journal.pgen.0030236
Puigserver P, Spiegelman BM (2003) Peroxisome proliferator-activated receptor-gamma coactivator 1 alpha (PGC-1 alpha): transcriptional coactivator and metabolic regulator. Endocr Rev 24(1):78-90. doi:10.1210/er.2002-0012

Puigserver P, Wu Z, Park CW, Graves R, Wright M, Spiegelman BM (1998) A cold-inducible coactivator of nuclear receptors linked to adaptive thermogenesis. Cell 92(6):829-839. doi:10.1016/S00928674(00)81410-5

Purcell S, Neale B, Todd-Brown K, Thomas L, Ferreira MA, Bender D, Maller J, Sklar P, de Bakker PI, Daly MJ, Sham PC (2007) PLINK: a tool set for whole-genome association and populationbased linkage analyses. Am J Hum Genet 81(3):559-575. doi:10.1086/519795

Rubinsztein DC, Leggo J, Chiano M, Dodge A, Norbury G, Rosser E, Craufurd D (1997) Genotypes at the GluR6 kainate receptor locus are associated with variation in the age of onset of Huntington disease. Proc Nat Acad Sci USA 94(8):3872-3876

Scarmeas N, Luchsinger JA, Mayeux R, Stern Y (2007) Mediterranean diet and Alzheimer disease mortality. Neurology 69(11):1084 1093. doi:10.1212/01.wnl.0000277320.50685.7c

Sofi F, Cesari F, Abbate R, Gensini GF, Casini A (2008) Adherence to Mediterranean diet and health status: meta-analysis. BMJ 337:a1344. doi:10.1136/bmj.a1344

Soyal SM, Felder TK, Auer S, Hahne P, Oberkofler H, Witting A, Paulmichl M, Landwehrmeyer GB, Weydt P, Patsch W (2012) A greatly extended PPARGC1A genomic locus encodes several new brain-specific isoforms and influences Huntington disease age of onset. Hum Mol Genet. doi:10.1093/hmg/dds177

St-Pierre J, Drori S, Uldry M, Silvaggi JM, Rhee J, Jager S, Handschin C, Zheng K, Lin J, Yang W, Simon DK, Bachoo R, Spiegelman BM (2006) Suppression of reactive oxygen species and neurodegeneration by the PGC-1 transcriptional coactivators. Cell 127(2):397-408. doi:10.1016/j.cell.2006.09.024

Taherzadeh-Fard E, Saft C, Andrich J, Wieczorek S, Arning L (2009) PGC-1alpha as modifier of onset age in Huntington disease. Mol Neurodegener 4:10. doi:10.1186/1750-1326-4-10

Taherzadeh-Fard E, Saft C, Akkad DA, Wieczorek S, Haghikia A, Chan A, Epplen JT, Arning L (2011) PGC-1alpha downstream transcription factors NRF-1 and TFAM are genetic modifiers of Huntington disease. Mol Neurodegener 6(1):32. doi:10.1186/ 1750-1326-6-32

The Huntington's Disease Collaborative Research Group (1993) A novel gene containing a trinucleotide repeat that is expanded and unstable on Huntington's disease chromosomes. Cell 72(6):971983. doi:0092-8674(93)90585-E

Warner JP, Barron LH, Brock DJ (1993) A new polymerase chain reaction (PCR) assay for the trinucleotide repeat that is unstable and expanded on Huntington's disease chromosomes. Mol Cell Probes 7(3):235-239. doi:10.1006/mcpr.1993.1034

Weydt P, Pineda VV, Torrence AE, Libby RT, Satterfield TF, Lazarowski ER, Gilbert ML, Morton GJ, Bammler TK, Strand AD, Cui L, Beyer RP, Easley CN, Smith AC, Krainc D, Luquet S, Sweet IR, Schwartz MW, La Spada AR (2006) Thermoregulatory and metabolic defects in Huntington's disease transgenic mice implicate PGC-1alpha in Huntington's disease neurodegeneration. Cell Metab 4(5):349-362. doi:10.1016/j.cmet.2006.10.004

Weydt P, Soyal SM, Gellera C, Didonato S, Weidinger C, Oberkofler H, Landwehrmeyer GB, Patsch W (2009) The gene coding for PGC-1alpha modifies age at onset in Huntington's disease. Mol Neurodegener 4:3. doi:10.1186/1750-1326-4-3 